\title{
Fundamentos
}

\begin{abstract}
Resumo
Propomos discutir o percurso que Frend trilhon até isolar e nomear o fenômeno da transferencia. Defendemos que uma importante condição para o surgimento da Psicanálise está na problematização da implicação ética por parte de quem conduz. o tratamento suscitado pelo encontro com as manifestações da transferência na clínica da bisteria. Nosso recorte compreende o periodo que vai do tratamento de Anna O., em 1880, até 1895.

Nesse interim, acompanhamos o ordenamento progressivo das questões concernentes à técnica analítica em torno do problema da transferência e questionamos os diversos usos do termo transferência até a sua conceituação. Descritores: transferência; afeto; linguagem; sugestão.
\end{abstract}

\section{A TRANSFERÊNCIA: DOS PRIMÓRDIOS DA PSICANÁLISE AOS ESTUDOS SOBRE HISTERIA $^{\top}$}

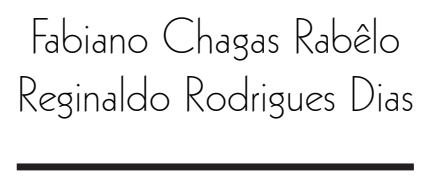

\section{Introdução}

$\mathbb{E}_{\text {ste artigo tem como objetivo discutir o percurso que Freud }}$ trilhou até isolar e nomear o fenômeno da transferência. Partimos do pressuposto de que uma das condições que possibilitaram o surgimento da Psicanálise está na problematização da implicação ética do analista no que concerne ao lugar que ocupa diante da fala

- Membro da Escola de Psicanálise dos Fóruns do Campo Lacaniano (EPFCL), Professor Assistente do Curso de Psicologia da Universidade Federal do Piaú (UFPI - Campus Parnaíba ), Parnaíba, PI, Brasil.

- a Professor Assistente do Curso de Psicologia da Universidade Federal do Piaú (UFPI), Teresina, PI, Brasil. 
que lhe é endereçada. Esse processo é correlato ao encontro com as manifestações da transferência na clínica da histeria.

Salientamos que, apesar de esse momento inaugural poder ser situado com Breuer ainda no início da década de 1880, o fenômeno da transferência só é nomeado e problematizado no último capítulo dos Estudos sobre histeria, com Freud, em 1895. Contudo, no espaço entre 1895 e 1905 o interesse pelo fenômeno da transferência nos textos freudianos é arrefecido. Percebemos nesse ínterim a utilização da palavra transferência de forma pouco específica na descrição de uma gama de processos psíquicos.

A partir de 1905, no posfácio do caso Dora, opera-se uma retomada da concepção de transferência estabelecida no final dos Estudos. Desse ponto em diante as referências à transferência ganham uniformidade conceitual, vindo a se beneficiar de aprofundamentos e novos arranjos. Por meio desse processo, a transferência gradualmente obtém o estatuto de um dos pilares da técnica psicanalítica.

Por razão de espaço, a proposta deste trabalho abarca apenas um recorte desse percurso da elaboração Freudiana. Isto é, o período que vai do tratamento de Anna O. até 1895. Iniciaremos com o resgate dos usos da palavra "transferência". Partindo daí, acompanharemos a discussão promovida por Freud sobre os fenômenos da clínica que serão ordenados em torno do conceito de transferência, a saber: sugestão, linguagem, interpretação, afeto, amor e pulsão.

Com isso, para além do recenseamento da utilização do termo transferência em um recorte da obra de Freud, propomos resgatar o campo discursivo onde os problemas formulados a partir da clínica são articulados em torno do manejo da transferência.

Durante nosso percurso, destacaremos a dimensão política e ética inerente à problematização do fenômeno da transferência. Do mesmo modo, discutiremos alguns aspectos metodológicos epistemológicos subjacentes à conceituação da transferência.

\section{Contextualização e recorte metodológico}

Muito antes de apresentar a transferência como um conceito basilar da técnica psicanalítica, Freud se utiliza em contextos diferentes da palavra "transferência". Por exemplo, nos Estudos sobre histeria e na Interpretação dos sonhos. 
Nos Estudos, encontramos vários empregos diferentes dessa palavra. Uma aparição pontual pode ser localizada em uma passagem do caso Emmy. Percebe-se aqui um sentido mais coloquial, desprovido de qualquer pretensão teórica ou técnica (Breuer \& Freud, 1895/1991, p. 97). Também encontramos a palavra "transferência" no decorrer da exposição do caso Elisabeth para descrever uma operação de linguagem que privilegia a expressão imagética e facilita a produção do sintoma conversivo na histeria (Breuer \& Freud, 1895/1991, p. 201).

Já no livro dos sonhos, identificamos o emprego desse termo na designação do processo de deslocamento de ênfase psíquica envolvido no trabalho do sonho. Encontramos nesse texto, em especial no capítulo 7 , repetidas referências ao substantivo "transferência" e ao verbo transferir (Freud, 1900/1999a, pp. 312, 537, 543, 552, 553, 562, 582 e 585).

Por fim, no último capítulo dos Estudos, é possível identificar o uso do termo "transferência" numa acepção muito próxima ao conceito que será desenvolvido no início da década de 1910. Entretanto, essa primeira aparição sintética do conceito não será imediatamente desenvolvida em toda sua potência.

Em breve, comentaremos o uso da palavra "transferência" nos Estudos mais minuciosamente. Por ora, gostaríamos de sublinhar que, tanto nos Estudos como no livro dos sonhos, é possível reconhecer nessas menções iniciais da palavra "transferência" uma intuição clínica e o início de um esforço de conceituação que irá pavimentar terreno para o trabalho conceitual de aprofundamento a partir de 1905, o que transformará significativamente a condução do tratamento analítico.

Que intuição clínica é essa? É o que chamamos de implicação ética do psicanalista no tratamento. Consideramos uma condição para a emergência do discurso psicanalítico que o analista, a partir de sua convicção na hipótese do inconsciente, participe do sintoma do analisando, transformando o sintoma bruto em sintoma analítico. A assunção desse lugar na clínica não ocorre sem uma mudança na economia psíquica da pessoa do analista.

Essa é a razão do receio de Freud em escrever um manual sobre técnica. No texto sobre análise selvagem, Freud (1910/1997a) salienta que os mesmos obstáculos encontrados na condução do tratamento de neuróticos também estão presentes na formação dos analistas. Por isso, defende que não é possível apreender a técnica sem uma transformação nas resistências internas do próprio analista. Tais resistências constituem a razão da ignorância do saber inconsciente.

Daí não basta o conhecimento teórico para que o analista praticante esteja suficientemente familiarizado com o uso da técnica da Psicanálise. De acordo com Freud, o saber-fazer que franqueia o uso da técnica só 
é atingido com sacrifício, tempo e esforço (Freud, 1910/1997a, p. 140).

Dando sequência à nossa proposta de trabalho, salientamos que, para além do resgate da discussão em torno do uso do termo "transferência", faz-se necessário realizar o levantamento das questões suscitadas pela clínica que, mais tarde, serão ordenadas em torno do conceito de transferência.

Dessa maneira, vemos aparecer nos textos de Freud, numa tentativa ainda embrionária de articulação desses elementos entre si, referências à pulsão, aos afetos, ao uso terapêutico da linguagem, à incidência da palavra no corpo, à interpretação, às manifestações amorosas (da vida comum e da infância), à resistência, à sugestão e à hipnose.

A respeito da sugestão, gostaríamos de salientar uma transformação que se processa em consonância com a nomeação do fenômeno da transferência. Até o posfácio do caso Dora (Freud, 1905/1997b), Freud acreditava ter anulado a influência da sugestão com o abandono da hipnose e a adoção da associação livre, como podemos ler em "O método psicanalítico freudiano" (Freud, 1904/1997c). Essa opinião é revista após um ciclo de revisão conceitual que ocupa a segunda metade da década de 1900. Por meio desse trabalho de reelaboração, o manejo da transferência ganha um lugar estratégico na condução do tratamento. Tal mudança produz como consequência imediata o reco- nhecimento da persistência residual dos efeitos da sugestão na clínica psicanalítica (Freud, 1912/1997d, p. 65).

A partir daí, faz-se necessário que o analista esteja advertido da incidência dos efeitos da sugestão na sua prática. Ou seja, que ele saiba reconhecê-los de modo a não os confundir com efeitos de análise. Em suma, a sugestão é percebida como um fenômeno indissociável da transferência e, consequentemente, da análise; contudo ela não constitui o móbil do trabalho analítico. Tal fato pode ser constatado no alerta sobre os desvios decorrentes do que denomina de técnica afetiva (Freud, 1912/1997e, p. 178) e na defesa do caminho da perlaboração das resistências como o diferencial do tratamento analítico. Ou seja, como aquilo que o distingue de outros tratamentos alicerçados na influência por sugestão (Freud, 1914/1997f, p. 214).

Isso leva a outro ponto estratégico de nossa empreitada, o de repensar a função da interpretação na análise. Freud inicialmente desenvolve uma técnica de interpretação para, em seguida, submetê-la ao manejo da transferência. Lembramos que até a segunda metade da década de 1900 ele respondia ao problema de "quando interpretar?" priorizando o argumento do derretimento (Schmelzen) ou superação (Überwindung) das resis ̈̈ tências (Breuer \& Freud, 1895/1991, pp. 284, 286, 300, 307). Esse argumento será conservado e enriquecido. Com o advento da transferência, uma 
nova perspectiva se abre. As referências técnicas já consolidadas a respeito da interpretação e das mudanças na economia psíquica produzidas em análise são ordenadas em torno desse novo operador clínico.

Por sua vez, a conceituação do fenômeno da transferência inicia um ciclo de questionamentos sobre a orientação ética da prática psicanalítica e sua incidência na cultura. Assim, Freud define a Psicanálise como a terceira ferida narcísica da humanidade, localizando essa ferida narcísica na constatação de que "o Eu não é o senhor em sua própria casa” (Freud, 1910/2001, p. 194, tradução nossa). Entendemos essa afirmativa como a intensificação do alcance de outra frase proferida quase duas décadas antes: que o Inconsciente constitui o "núcleo de nosso ser" (Freud, 1900/1999a, p. 590, tradução nossa) e que esse núcleo é atravessado pela falta que subjaz à busca alucinatória de satisfação inerente ao funcionamento do processo primário.

Daí, na prática psicanalítica, em contraste com o ideal iluminista de emancipação, não se trata de restituir a soberania do Eu pela via do pensamento racional consciente, mas de produzir uma atualização e articulação simbólica da falta que habita o âmago do nosso ser.

Além disso, pela via da transferência, enveredamos na problematização da materialidade da Psicanálise e dos modos de manifestação do inconsciente no campo da sexualidade, do amor, das palavras e dos afetos. Trata-se daquilo que Freud denomina de evidência da etiologia sexual das neuroses (Freud, 1914/1999b, p. 50).

Consideramos importante tecer alguns comentários acerca da demonstração dessa evidência na clínica. Freud possuía uma vasta vivência em estudos anatômicos e farmacológicos, assim como uma sólida formação no método científico de pesquisa (Gay, 1989). Levantamos essa questão, pois a convicção freudiana que norteia o seu projeto de investigação não é respaldada em uma pesquisa experimental homóloga ao procedimento científico tradicional.

Freud não menosprezava a importância do método experimental, mas, como teremos em breve a oportunidade de destacar, ele, desde o seu texto sobre o tratamento psíquico (Freud, 1890/1997g), já apontava para a insuficiência dos métodos científicos de sua época para tratar e investigar as doenças nervosas. Assim, o desenvolvimento da concepção de transferência pressupõe o deslocamento de ênfase: de um processo de demonstração experimental para uma investigação que se pauta nos próprios fenômenos desvelados pela clínica. Por conseguinte, mesmo após se distanciar do método experimental de pesquisa, Freud sustenta a presença de um fundamento material e de um processo lógico de demonstração da clínica psicanalítica, logo, de sua transmissão.

Feito esse preâmbulo, propomos a distinção de três momentos de elaboração do fenômeno da transferência em Freud: 1) uma etapa onde encontramos 
o início de um esforço de conceituação, que se desenvolve em paralelo com outras aplicações do termo transferência (que situamos entre 1880 até 1905); 2) um período em que o emprego do termo "transferência" ganha uniformidade e o fenômeno da transferência passa a ser priorizado como um elemento fundamental na condução do tratamento. Isso pode ser constatado na leitura dos casos clínicos publicados nesse período (entre 1905 e 1911); e 3) um ciclo de aprofundamento e obtenção de rigor conceitual (a partir de 1912).

Neste artigo, vamos nos deter ao primeiro desses três momentos ou, para ser mais específico, a um recorte dessa etapa (entre 1880 a 1895). Nossa exposição, para fins didáticos, será organizada em torno de dois tópicos, cada um deles correspondendo a períodos cronológicos da elaboração freudiana.

O primeiro tópico tratará da década de 1880. Seu foco recairá na discussão realizada por Freud sobre o caso Anna O. Aqui, faremos referência a textos mais tardios de Freud que abordam esse momento retroativamente, situando nele os efeitos do fenômeno da transferência. $\mathrm{O}$ segundo tópico abrangerá a primeira metade da década de 1890. Nele comentaremos mais minuciosamente dois textos: Tratamento psíquico ou animico e Estudos sobre histeria.

Pretendemos em outra oportunidade prosseguir do ponto de onde paramos, contemplando o período que vai de 1896 até o caso Dora, em 1905.

\section{A transferência no tratamento de Anna O.}

Freud (1914/1999b), na história do movimento psicanalítico, descreve como inevitável a instauração da transferência no tratamento de neuróticos. Para ele, no cerne da transferência encontram-se as forças pulsionais de natureza sexual. Daí afirmar que tal fenômeno constitui a prova inabalável da etiologia sexual das neuroses. Podemos acrescentar: uma prova do inconsciente.

No mesmo texto, defende que o primeiro contato com o fenômeno da transferência desempenhou um papel fundamental no surgimento da Psicanálise. Situa essa experiência inaugural no único tratamento conduzido por Breuer sob a orientação do método catártico.

A ideia de que o reconhecimento das manifestações da transferência no tratamento de Anna O. representa um momento estratégico 
na descoberta da Psicanálise é expressa de modo enfático na primeira das cinco lições sobre Psicanálise (Freud, 1910/2001). Em função da importância desse tratamento, Freud credita a Breuer o mérito de ter trazido a Psicanálise à luz, o que suscitou fortes protestos da parte de seu antigo colaborador.

Freud (1914/1999b) apresenta mais detalhes sobre esse momento decisivo. Ao problematizar a enigmática facilitação da terapêutica engendrada na relação entre Breuer e sua paciente, Freud vislumbra na disposição à sugestão por parte de Anna O. indícios de uma força psíquica que almeja expressar-se e atualizar-se.

Em diversos momentos do tratamento, essa tendência encontra condições favoráveis para produzir mudanças subjetivas. É o que se atesta na leitura dos dois últimos parágrafos desse caso clínico (Breuer \& Freud, 1895/1991). Neles, Breuer descreve a sua participação como "inventor" do método catártico. A partir desse relato, podemos afirmar que a descoberta do método catártico foi franqueada pelo consentimento de Breuer em acompanhar com sua escuta o movimento espontâneo da fala de Anna O. Com o desenrolar dos acontecimentos, Breuer consegue chegar à descrição de uma nova técnica terapêutica. Ele próprio se diz surpreso com o produto do que chama de "sequência de resoluções espontâneas" ("Reibe spontaner Erledigungen") (Breuer \& Freud, 1895/1991, p. 66, tradução nossa).

Nesse ponto, a terapêutica de Breuer encontra sua potência. O surpreendente é que essa potência é circunstancial e, em parte, possibilitada por um consentimento fundado na ignorância, fruto do recalque. De qualquer forma, trata-se de uma postura radicalmente diferente da que encontramos desenvolvida no capítulo teórico redigido pelo mesmo autor, onde é inevitável a constatação de um retrocesso em relação a sua atitude inicial.

Se na exposição do caso de Anna O. as elaborações teóricas e as inovações técnicas são produtos de uma escuta que colocava em evidência o saber produzido pela fala da paciente de Breuer, no penúltimo capítulo dos Estudos a situação é outra. Nele, as contribuições fundamentadas na experiência clínica são rarefeitas, ao passo que proliferam referências a hipóteses fisicalistas, o que acaba por obliterar o poder subversivo originalmente presente no seu método.

Freud (1914/1997f) reconstitui as transformações da atitude de Breuer perante suas investigações clínicas no caso de Anna O. e 
localiza um ponto de virada. Segundo ele, ao se defrontar com o acirramento do elemento sexual que permeava a relação com sua paciente, Breuer recua e caracteriza essas manifestações transferenciais como um obstáculo ao prosseguimento do tratamento. De acordo com Freud, um "untoward event” (Freud, 1914/1999b, p. 49).

Freud (1910/2001), por sua vez, diz ter continuado as investigações do ponto onde Breuer interrompeu. Refere ter prosseguido à própria custa pelo caminho que Breuer apontou e, ao mesmo tempo, repudiou, assumindo toda a responsabilidade pelo resultado das investigações.

Podemos afirmar daí que, no tratamento de outros pacientes histéricos, Freud se deparou com o mesmo obstáculo - o mesmo evento funesto - que levou Breuer a abdicar do tratamento de Anna O. Daí, a emergência da transferência não poder ser qualificada como um acidente, um fato circunstancial e localizado. Antes de tomar a transferência como um obstáculo ao tratamento, ele incorpora as manifestações desse fenômeno ao cerne da técnica de sua proposta de tratamento.

Para Freud, Breuer se depara com o fato de que, da parte do analista, a transferência não é anônima. Ela exige uma implicação, uma orientação, um lastro no desejo de quem se espera a condução do tratamento.

Concluímos do exposto que a instauração de uma nova resposta diante do fenômeno da transferência constituiu um ato significativo que franqueou o caminho para a constituição do discurso analítico. Tal fato não deixa de ser surpreendente, uma vez que o termo "transferência", na forma como veio a se consolidar a partir de 1912 - na condição de um conceito estratégico da técnica analítica - é delineado pela primeira vez capítulo final dos Estudos (Breuer \& Freud, 1895/1991). Ainda assim, nos textos freudianos até 1905, a transferência permanece como uma referência desprovida de uma unidade conceitual, ocupando um lugar coadjuvante na discussão teórica e técnica.

\section{A primeira metade da década de 1890: tratamento psíquico (ou anímico)}

Nesta parte do trabalho comentaremos dois textos que consideramos essencial para o entendimento do processo de formação dos primeiros rudimentos da técnica que irá constituir a base do conceito de transferência. São eles Tratamento psíquico ou anímico e Estudos sobre histeria.

No primeiro desses textos, Freud (1890/1997g) expõe o projeto de superar a dicotomia entre corpo e mente presente na abordagem médica dos fenômenos patológicos. Para isso, propõe uma investigação cientificamente orientada das chamadas “doenças dos nervos" pela via de um tratamento alicerçado na fala. 
Segundo Freud, a etiologia das doenças nervosas não residia numa afecção global do sistema nervoso central tal como era preconizado por muitos de seus colegas médicos. A partir daí conclui que, assim como a definição da etiologia dessas doenças estava equivocada, os métodos utilizados para o tratamento - os mesmos empregados para doenças fisiológicas - revelavam-se inadequados.

Para ele, as doenças dos nervos são qualitativamente diferentes das fisiológicas. Tal constatação, entretanto, não justifica a adoção de uma explicação transcendental. Sua atitude é a de prosseguir de modo lógico, científico e rigoroso na investigação de fenômenos concretos da clínica.

Com isso, Freud se põe a procurar na materialidade das manifestações das doenças nervosas um elemento que esclareça o enigma de sua etiologia. A solução desse enigma assentaria os fundamentos metodológicos de uma terapêutica. É assim que a palavra “Wort” (Freud, 1890/1997g, p. 17) é elevada à condição de alicerce e ponto de partida da investigação freudiana.

Nesse contexto, Freud se dedica ao estudo dos afetos e dos efeitos da fala no corpo. Os afetos, segundo ele, surgem a partir da ação da palavra no corpo. Eles tornam-se perceptíveis apenas a partir das manifestações corporais que lhes são inerentes. Em alguns momentos tais manifestações são discretas (nas mudanças de estados de humor, por exemplo); no entanto, mesmo nesses casos, uma alteração corporal está presente. Dessa forma, corpo e palavra encontram-se enodados na mesma explicação dos processos psíquicos.

As palavras, nesse contexto, tornam-se a principal ferramenta de intervenção. Elas, escreve Freud, mobilizam "muitas forças pulsionais genuinamente humanas" ("mehere echt menschliche Triebkeräft') (Freud, 1890/1997g, p. 24, tradução nossa). Defende que os efeitos da mediação dessas forças pela palavra podem ser aferidos nas práticas religiosas, nas relações em grupo, no enamoramento, na hipnose e na sugestão.

Os dois últimos procedimentos, especificamente, constituem para Freud a oportunidade de investigar de forma metódica e orientada os efeitos da palavra no corpo. De acordo com ele, a ação da hipnose e da sugestão presentifica de modo incontestável a afetação do corpo pela palavra. Lembramos que o uso desses recursos, nessa época, era visto com suspeição por uma 
considerável parcela da comunidade científica.

Essa via de investigação possibilita a Freud questionar um fenômeno amplamente reconhecido pela comunidade médica, mas também igualmente negligenciado: a relação médico-paciente como um fator de enorme relevância na promoção da cura. Sustenta a importância da livre escolha do médico pelo paciente, defendendo que a personalidade do médico constitui o principal elemento catalisador de uma tendência do doente à formação de vínculos terapêuticos.

É assim que reconhece no doente uma tendência à cura (Streben nach Genessung) que se conjuga à confiança (Zutrauen) depositada no médico, produzindo efeitos terapêuticos que extrapolam aos engendrados pelo tratamento fisicalista. Reitera que a fonte dessa força que impulsiona a cura não está do lado do médico, mas do paciente. E arremata: trata-se de uma tendência inerente ao humano (rein menschlichen Zuneigung) (Freud, 1890/1997g, p. 25, tradução nossa) que é despertada pela presença do médico.

Para Freud, essa modalidade de tratamento - a cura pela fala - é a mais antiga na história da humanidade e precede o advento do discurso científico. Sua proposta, contudo, não é a de retroagir a uma explicação pré-científica dos fatos, mas constituir uma nova forma - moderna e racional - de tratamento psíquico 
(zielbewusste moderne Seelenbehandlung) (Freud, 1890/1997g, p. 35, tradução nossa). Daí sua conclusão: a condução do tratamento anímico não deve ser abandonada à sorte do doente. Cabe ao médico utilizar-se desse recurso com ética e rigor científico para a promoção da cura.

Sem se esquecer das limitações e obscuridades concernentes aos efeitos da hipnose e da sugestão - por exemplo, a sua aplicabilidade seletiva, o seu caráter transitório e efêmero, além da insuficiência de conhecimento a respeito de sua dirigibilidade - Freud se pergunta pela possibilidade do uso terapêutico desses recursos no tratamento das doenças nervosas. No escopo dessa discussão, investiga alguns fenômenos da vida psíquica normal em que é possível identificar efeitos análogos aos produzidos pela hipnose e a sugestão.

Nesse ponto, é surpreendente constatar a forma intuitiva e contundente pela qual Freud problematiza a relação íntima entre os efeitos da linguagem e as vicissitudes do psiquismo. Em seus exemplos, ao se questionar sobre o poder da palavra na hipnose, articula o estado psíquico produzido pela hipnose com a atitude de submissão encontrada "nas crianças diante de seus pais amados" (Freud, 1890/1997g, p. 30, tradução nossa). Além disso, apresenta essa atitude como análoga às situações de enamoramento da vida adulta.

É nesse momento que, ao discutir os limites da hipnose, Freud esboça as primeiras considerações sobre o fenômeno da resistência psíquica. Primeiro, a partir de sua prática, refuta a concepção do senso comum de que, na hipnose, ao se alcançar um estado de sonambulismo profundo, obterse-ia do mesmo modo um poder irrestrito de influência por sugestão. Segundo ele, mesmo nos estados mais profundos de hipnose encontra-se uma força que se opõe ao poder de sugestão do hipnotizador.

Que força seria essa? Freud não responde, mas aponta alguns caminhos de investigação. Transcrevemos aqui um trecho que consideramos relevante:

mesmo na melhor hipnose, a sugestão não exerce um poder ilimitado, mas apenas de uma determinada força. Somente pequenos sacrifícios são ofertados pelo hipnotizado; quando se trata de grandes (sacrifícios) ele recua, tal como ocorre na vigília (Freud, 1890/1997g, p. 34, tradução nossa).

Em seguida, acrescenta: quando se impulsiona o hipnotizado "através da sugestão a abdicar de sua doença, então se percebe que, para ele, isto (abrir mão da doença) representa um grande sacrifício, e não um pequeno" (Freud, 1890/1997g, p. 34, tradução nossa).

Acreditamos que essa citação denota a convicção freudiana de que, nas doenças dos nervos, o sintoma exerce uma função estratégica na economia psíquica. Temos aí evidências da divisão psíquica do neurótico, uma 
vez que o adoecimento é tomado como algo que mobiliza sofrimento, mas, paradoxalmente, também ocupa um lugar de alto valor na organização psíquica.

Aqui Freud nomeia o fenômeno da resistência (Widerstand) (Freud, 1890/1997g, p. 34). Nesse momento, ela constitui uma reação psíquica refratária à mudança quando algo de grande intensidade psíquica encontra-se ameaçado. Trata-se, portanto, de um fenômeno inerente ao tratamento das doenças dos nervos, que denota uma implicação indissociável do sujeito com seu sintoma.

Nesse ponto da discussão, Freud persegue diligentemente a trilha dos fenômenos que evidenciam a divisão psíquica do neurótico. É por isso que se interessa pelos efeitos da sugestão pós-hipnótica. Tratase, nesse caso, de uma modalidade de sugestão em que a influência do comando verbal proferido sob hipnose só se manifesta depois de encerrado o estado de sonambulismo.

Freud encontra nesse fenômeno a confirmação de que a sugestão não se explica pelos fenômenos fisiológicos do sono. Mais ainda: a resposta dos hipnotizados quando indagados sobre a razão de suas ações previamente sugestionadas atestam a divisão psíquica que é solidária à influência indelével da fala no corpo. Quando questionados sobre a razão de uma determinada ação pós-sugestionada, respondem que sua atitude fora orientada por um impulso súbito e obscuro ou simplesmente alegam outra razão qualquer em substituição à lembrança inacessível do comando sugestivo.

\section{A primeira metade da década de 1890: estudos sobre histeria}

Ao longo dos casos clínicos publicados nesse livro, Freud promove mudanças significativas no modo de conceber os fenômenos histéricos e o método terapêutico. Faremos um pequeno resumo de algumas dessas transformações que consideramos mais importantes para o entendimento da construção do conceito de transferência.

A principal mudança diz respeito à defesa da etiologia psicogênica da histeria, o que culmina na formulação da hipótese traumática. Enquanto Breuer sustenta uma etiologia hereditária e congênita da histeria, Freud enfatiza a aquisição acidental, concedendo ao trauma um peso maior nesse processo de aquisição. $O$ trauma é definido 
como um fenômeno psicológico, um excedente em relação à capacidade psíquica de elaboração das quantidades de afetos.

Uma mudança significativa se dá quando Freud distancia-se do modelo de divisão psíquica de Breuer, que pressupunha duas consciências - uma dessas, patológica - que não se comunicavam uma com a outra. Isso abre as portas para uma intervenção em vigília, sem o uso da hipnose. Trata-se do que Freud chamou de "análise psíquica" (Breuer \& Freud, 1895/1991, p. 121). Uma espécie de procedimento técnico precursor da associação livre.

A consequência dessa transformação na técnica é que, diferena temente de Breuer, a terapêutica de Freud amplia seus objetivos para além da promoção da ab-reação, visando também uma elaboração do trauma pela fala.

É assim que descobre na "segunda consciência" de Breuer não uma consciência defectiva, mas outra modalidade de pensamento com sua gramática e organização próprias. Temos nesse momento a nomeação do inconsciente como uma instância psíquica ordenada em torno de uma sintaxe diferente daquela do pensamento da consciência. Essa outra instância psíquica possui, portanto, uma intencionalidade, um propósito.

Ao perseguir as manifestações dessa intencionalidade na fala dos seus pacientes histéricos, em especial Emmy e Lucy, Freud descobre a presença de uma força contrária à expressão do inconsciente e salienta que essa força está em exercício mesmo nos estados mais profundos de sonambulismo e hipnose.

É assim que reconhece na sintomatologia de seus pacientes a expressão dos pensamentos inconscientes distorcidos pelo efeito da resistência. Afirma então que a origem dessa resistência pode ser encontrada na censura exercida pelo sistema eu-consciência que impede a expressão do inconsciente.

Esse passo torna possível a investigação dos motivos da censura. O processo terapêutico de superação das resistências pela elaboração através da fala desvela que os conteúdos inconscientes são recalcados por representarem uma modalidade de satisfação sexual que entra em conflito com os padrões morais do Eu. Daí o sexual estar sinergicamente conjugado ao núcleo traumático da neurose e do inconsciente. Esse elemento sexual em questão remete, pela rememoração promovida pelo método catártico, a uma sexualidade infantil, cujos contornos e expressões se mostram diferentes da sexualidade do adulto. 
Com isso, Freud enuncia o sentido do trabalho terapêutico: ele caminha na mesma direção da insistência do inconsciente em se expressar e em oposição ao funcionamento da censura e do recalque. A elaboração psíquica do conteúdo recalcado não ocorre sem a mobilização de uma quota de angústia.

Nos Estudos, encontramos diferentes menções à palavra "transferência". Situaremos aqui, em função de sua importância, os diversos contextos de sua aparição no texto.

Diante de uma melhora circunstancial de alguns de seus sintomas, Emmy interrompe o tratamento e retorna à sua cidade. Sete meses depois, Freud recebe notícias dela por intermédio de Breuer. Sua filha adoecera de problemas em parte psicológicos, em parte fisiológicos. Freud então recebe a filha de Emmy para tratá-la e recomenda um médico ginecologista para acompanhá-la. Algum tempo depois, a filha de Emmy opta por trocar de médico e recebe outro diagnóstico e tratamento.

Nesse momento, Emmy se dirige a Freud com a queixa de que ambos - ele e o ginecologista recomendado - subestimaram o sofrimento de sua filha e não lhe dedicaram o cuidado necessário. Através de sua queixa, Emmy expressa a Freud uma cadeia de pensamentos (Gedankenwege) que até então ele não fora capaz de perceber (nicht nachgespürt habe) (Breuer \& Freud, 1895/1991, p. 96, tradução nossa).
Emmy conclui que sua filha fora enganada pelos dois médicos. Breuer e outro médico próximo a Freud tentam, sem sucesso, intervir como mediadores do conflito. Tal situação culmina no agravamento dos sintomas de Emmy.

Após uma nova crise, Emmy é recomendada a outro médico que atendia em um sanatório mais distante e que fora instruído na aplicação do método catártico. Freud escreve: "Essa tentativa de uma transferência [de medicos] fracassa radicalmente" ("Dieser Versuch einer Uberträgung misslang gan zründlich”) (Breuer \& Freud, 1895/1991, p. 96, tradução nossa).

Durante sua estadia nessa instituição ocorre uma piora significativa de seu estado. Isso é explicado por Freud pelo fato de que Emmy, desde o começo, não se entendeu com o novo médico, o que produziu resistências (Widerstande) contra todas as propostas de tratamento que lhe eram oferecidas (Breuer \& Freud, 1895/1991, p. 96).

Nessas circunstâncias, recebe a visita de uma amiga. Esta, ao constatar o estado deplorável de Emmy - que apresentava transtornos graves de sono e de apetite -, ajuda-lhe a fugir do sanatório e a retornar para casa. Pouco tempo depois, Emmy está de volta a Viena e novamente sob os cuidados de Freud. Inicia-se então um novo ciclo de seu tratamento.

Freud percebe em torno dessa dificuldade de transferir a paciente aos cuidados de outro médico uma 
vinculação especial de Emmy à sua pessoa. Através desse vínculo, acontece a mobilização de um saber até então não articulado. A expressão desse saber foi acompanhada por um estado afetivo intenso, correlato da manifestação de uma força de resistência psíquica.

A palavra "transferência" também pode ser encontrada na exposição do caso Elisabeth. Aqui ela designa o processo de transposição das representações verbais em imagens para favorecer a formação do sintoma histérico através da conversão (Breuer \& Freud, 1895/1991, p. 201).

\title{
Para concluir: o primeiro ciclo de conceituação da transferência
}

Ao final dos Estudos, no capítulo "A psicoterapia da histeria”, Freud chega a uma primeira definição da transferência bem próxima da acepção que esse termo irá adquirir a partir de 1905. A transferência (Breuer \& Freud, 1895/1991, pp. 319, 321) é descrita como uma "Mesalliance", uma falsa ligação (Freud, 1895/1991, p. 320), que se estabelece entre o médico e o paciente através da qual conteúdos patogênicos são mobilizados sob a oposição de uma força que impede a sua expressão. $\mathrm{O}$ afloramento das resistências produzido por esse vínculo paradoxal produz a atualização do recalcado e, com isso, a possibilidade de superação das resistências.

TRANSFERENCE: FROM THE VERY BEGINNING OF PSYCHOANALYSIS UNTIL THE STUDIES OF HISTERY

\begin{abstract}
We discuss the way followed by Freud until he discriminates the phenomenon of transference. We argue that an important condition to the rising of psychoanalysis is the question about ethical implication by those who conduct the treatment. It might be well observed by means of the perception of the clinical manifestation of the transference in hysterics' treatment. Our methodological approach comprises the period of Anna O.'s treatment, starting in 1880, until 1895. In these meantime, we follow the progressive ordering of the problems concerning the analytical technique around the transference's questions. We also discuss about the different uses of the term transference until it becomes a concept.
\end{abstract}

Index terms: transference, language, affection, suggestion.

TRANSFERENCLA: DE LO COMIENZO DE PSICOANÁLISIS HASTA ESTUDIOS SOBRE HISTERIA

\section{REsÚMEN}

Nosotros proponemos discutir el camino andado por Freud hasta aislar y nombrar el fenómeno de la transferencia. Nosotros sostenemos que una condición importante para la aparición del Psicoanálisis es cuestionar las implicaciones 
éticas de quien conduce el tratamiento. Esto se logra mediante el encuentro con las manifestaciones clinicas de la transferencia en la histeria. Nuestro recorte comprende el periodo de tratamiento de Anna O., en 1880, hasta 1895. Investigamos el organización progresiva de las cuestiones de la técnica de la análisis alrededor del problema de la transferencia. Además cuestionamos los diversos usos del término transferencia basta su conceptualización.

Palabras clave: transferencia; afecto; linguagem; sugestão.

\section{REFERENNCIAS}

Breuer, J., \& Freud, S. (1991). Studien über bysterie. Frankfurt, Deutschland: Fischer Taschenbuch Verlag. (Trabalho original publicado em 1895)

Freud, S. (1997a). Über wilde Psychoanalyse. In S. Freud, Studienausgabe (A. Mitscherlich, A. Richards, \& J. Strachey, hrsg., Ergänzungsband, s. 133-143). Frankfurt, Deutschland: S. Fischer Verlag. (Trabalho original publicado em 1910)

Freud, S. (1997b). Bruchstück einer Hysterie-Analyse. In S. Freud, Studienausgabe (A. Mitscherlich, A. Richards, \& J. Strachey, hrsg., Bd. VI, s. 83-187). Frankfurt/ Main: Deutschland: S. Fischer Verlag. (Trabalho original publicado em 1905)

Freud, S. (1997c). Die Freudsche psychonalytische Methode. In S. Freud, Studienausgabe (A. Mitscherlich, A. Richards, \& J. Strachey, hrsg., Ergänzungsband, s. 99-107). Frankfurt, Deutschland: S. Fischer Verlag. (Trabalho original publicado em 1904) Freud, S. (1997d). Zur Dynamik der Übertragung. In S. Freud, Studienausgabe (A. Mitscherlich, A. Richards, \& J. Strachey, hrsg., Ergänzungsband, s. 157-169). Frankfurt, Deutschland: S. Fischer Verlag. (Trabalho original publicado em 1912)

Freud, S. (1997e). Ratschläge für den Arzt bei der Psychoanalytische Behandlung. In S. Freud, Studienausgabe (A. Mitscherlich, A. Richards, \& J. Strachey, hrsg., Ergänzungsband, s. 169-181). Frankfurt, Deutschland: S. Fischer Verlag. (Trabalho original publicado em 1912)

Freud, S. (1997f). Erinnern, Wiederholen und Durcharbeiten (Weitere Rätschlage zur Technik der Psychoanlyse II). In S. Freud, Studienausgabe (A. Mitscherlich, A. Richards, \& J. Strachey, hrsg., Ergänzungsband, s. 205-215). Frankfurt, Deuts $\theta$ chland: S. Fischer Verlag. (Trabalho original publicado em 1914)

Freud, S. (1997g). Psychische behandlung (Seelenbehandlung). In S. Freud, Studienausgabe, (A. Mitscherlich, A. Richards, \& J. Strachey, hrsg., Ergänzungsband, s. 13-37). Frankfurt, Deutschland: S. Fischer Verlag. (Trabalho original publicado em 1890)

Freud, S. (1999a). Die Traumdeutung. In S. Freud, Studienausgabe (A. Mitscherlich, A. Richards, \& J. Strachey, hrsg., Bd. II.). Frankfurt, Deutschland: S. Fischer Verlag. (Trabalho original publicado em 1900)

Freud, S. (1999b). Zur Geschichite der psychoanalytischen Bewegung. In S. Freud, Gesammelte Werke (Bd X, pp. 41-112). Frankfurt, Deutschland: S. Fischer Verlag. (Trabalho original publicado em 1914)

Freud, S. (2001). Über Psychoanalyse. In S. Freud, Abriss der Psychoanalyse (pp. 105154). Frankfurt, Deutschland: S. Fischer Verlag. (Trabalho original publicado em 1910)

Gay, Peter. (1989). Freud: uma vida para nosso tempo. São Paulo: Companhia das Letras. 


\title{
NOTA
}

1. Esse trabalho é produto do projeto de pesquisa inscrito na Universidade Federal do Piauí (UFPI - campus Parnaíba) intitulado "A técnica psicanalítica: sua origem, sua ética e seus desdobramentos na atualidade".

\author{
ffabrabelo@hotmail.com \\ Rua Marc Jacob, 484/203 \\ 64202510 - Parnaíba - PI - Brasil. \\ regydyas@hotmail.com \\ Avenida José Bastos, 4717/301 \\ 60442105 - Fortaleza - CE - Brasil. \\ Recebido em abril/2013. \\ Aceito em junho/2013.
}

590 Estilos clin., São Paulo, v. 18, n. 3, set./dez. 2013, 574-590. 